\title{
Welcome to a Pink and Blue World! An Analysis of Gender-Typed Content in Birth Announcement Cards From 1940-2019 in the Netherlands
}

\author{
Joyce J. Endendijk ${ }^{1}$ (I)
}

Accepted: 22 September 2021 / Published online: 11 October 2021

(c) The Author(s) 2021

\begin{abstract}
There is a longstanding tradition in the Netherlands to announce the birth of a child by sending out birth announcement cards to friends and family. These cards provide a glimpse of the 'zeitgeist' over the years regarding gender through the way in which the birth of a son or a daughter is announced. The current study examined the gender-typed content of birth announcement cards from 1940 until 2019. To this end, 4669 birth announcement cards were coded based on the following categories: gender of baby, use of color, different types of images, and different types of text. Logistic regression analyses revealed that boy cards were more likely than girl cards to include blue as the dominant color, masculine descriptions of the baby, and parental expressions of pride. Girl cards were more likely than boy cards to include pink as the dominant color and images of flowers. Over time there was a decrease in the inclusion of masculine descriptions on boy cards, as well as the likelihood that fathers were mentioned before mothers. However, the expression of pride on boy cards increased over time. Overall, the amount of gender-typed content in birth announcement cards was minimal. Birth announcement cards which included gender-typed content tended to reflect gender stereotypes and different expressions for boys and girls in subtle ways that continue to reinforce gender stereotypes.
\end{abstract}

Keywords Gender stereotyping $\cdot$ Gender socialization $\cdot$ Archival $\cdot$ Birth announcement $\cdot$ Content analysis

After the birth of a child, it is customary in the Netherlands to send out birth announcement cards to friends, family, and acquaintances (Noorlandt, 2019). This tradition originated in the late 1800's in high-class families, but since 1950 almost all new parents sent out birth announcement cards (Noorlandt, 2019). Even though many parents nowadays announce the (imminent) birth of their child via social media (Leaver \& Highfield, 2018), almost all Dutch parents still send out birth announcement cards. In general, birth announcement cards provide information about the child that is born (e.g., date of birth, name, parents, brothers, sisters, gender) and often include illustrations and poems. Parents in the Netherlands have a wide range of gender-typical and gender-neutral options regarding the birth announcement cards available to them (Kessel \& Kooger, 1996; Koningkaart,

Joyce J. Endendijk

j.j.endendijk@uu.nl

1 Child and Adolescent Studies, Utrecht University, Heidelberglaan 1, 3584 CS Utrecht, The Netherlands n.d.), particularly with the introduction of websites through which parents can customize their own cards.

Yet, birth announcement cards might be a source of gender-typed content (e.g., pink for girls, blue for boys), as one of the most important facts revealed in birth announcements is whether the newborn is a boy or a girl (Gonzalez \& Koestner, 2005). Past research has demonstrated that parents' knowledge of the child's gender is associated with selecting more gender-typed toys, clothes, books, designs for rooms (Pomerleau et al., 1990), and children's names (Barry \& Harper, 1995). Parents' knowledge of the child's gender may also influence parents' choices about the content of birth announcement cards and reflect their views of gender and gender stereotypes (West, 2010). The current study builds on past research that examined the gender content of birth congratulation cards (Bridges, 1993; Christodoulou \& Lac, 2021; Willer, 2001) and birth announcements in newspapers (Gonzalez $\&$ Koestner, 2005) to investigate the gender-typed content of birth announcement cards from 1940 to 2019 in the Dutch context. 


\section{Early Parental Gender Socialization}

Parental socialization of gender in children refers to the ways in which parents influence children's gender development and shape their understanding of societal gender norms and expectations (Endendijk et al., 2018). Parents' endorsement of gender stereotypes has been associated with the way parents communicate about gender with their children (Endendijk et al., 2014), toys purchases (Weisgram \& Bruun, 2018), choosing traditional surnames for their children (Johnson \& Scheuble, 2002), and differential use of physical discipline with sons and daughters (Endendijk et al., 2017). Though these gender socialization practices are typically studied after children are born (Endendijk et al., 2018), there are indications that this process commences even before birth. For instance, knowing the fetal sex was associated with pregnant women talking to the unborn child in a gendered manner ("How is mommy's sweet girl doing in there?"), using gendered pronouns, and calling the unborn child by a gendered given name (Barnes, 2015). In addition, parents often choose a name for their child before birth, with most names being gendered in nature (Lieberson et al., 2000), and gender-typed name choices are associated with later gender-specific treatment of children by parents (Erwin, 1995). Notably, these forms of parental gender socialization have been associated with gender differences in language skills (Pruden \& Levine, 2017), academic achievement (Updegraff et al., 1996), occupational preferences (Sandberg et al., 1991), and problem behaviors in children (Endendijk et al., 2017) in later child development. To reduce or prevent gender inequality in these domains it is important to gain more insight into early forms of gender socialization.

\section{Gender-Typed Content in Birth Announcement Cards}

The current study relies on the gendered-family process model to identify several processes that might play a role in the gender-typed content that parents include in birth announcement cards (Endendijk et al., 2018). The first process is channeling or shaping, which refers to creating a gendered environment for children by the toys, clothes, activities, and chores parents choose for them (Crouter et al., 1995; Fisher-Thompson, 1993; Pomerleau et al., 1990). For instance, some studies have found that boys are provided with more male-typed toys, such as sports equipment, tools, and vehicles, whereas girls are provided with more female-typed toys such as dolls, jewelry, and child's furniture (MacPhee \& Prendergast, 2019; Pomerleau et al., 1990). In addition, the color pink has been found to be more dominant in girls rooms and clothes, whereas blue is more dominant in boys rooms and clothes (Pomerleau et al., 1990). Applied to the context of birth announcement cards, cards for boys and girls might differ, for example, in the toy illustrations that are depicted, or the colors used. Content analysis of birth congratulation cards revealed that blue was used most in cards for boys, whereas pink was used most in cards for girls (Bridges, 1993; Christodoulou \& Lac, 2021; Willer, 2001). In addition, masculine toys (e.g., balls, vehicles) were included more in boy cards, whereas no differences were found between girl and boy cards for feminine toys (e.g., dolls; Bridges, 1993; Willer, 2001). One study also found that baby accessories (e.g., bottles, bibs, pacifiers) were depicted more on girl cards than on boy cards (Willer, 2001), whereas other studies did not find this difference (Bridges, 1993; Christodoulou \& Lac, 2021).

The second process is the use of gendered language such as gender labels (Endendijk et al., 2014; Gelman et al., 2004). Use of gender labels in birth announcement cards might highlight gender as an important and salient category (Gelman et al., 2004). Similarly, children whose parents frequently use gendered language will be highly aware of gender categories, which shapes children's construction of their own gender concepts (Liben \& Bigler, 2002). Indeed, frequent use of gender labels by teachers in combination with other gender emphasizers (i.e., gendered organization and physical separation in classrooms) appears to increase children's gender stereotypes (Hilliard \& Liben, 2010). Furthermore, explicitly labeling gender was found to improve toddlers' categorization of people on the basis of gender (Diesendruck \& Deblinger-Tangi, 2014). Research specifically on parents' use of gender labels has demonstrated a male labeling bias during picture book reading, with male gender labels being used more often than female gender labels (DeLoache et al., 1987; Gelman et al., 2004). This male bias in labeling is visible to some extent in most languages and highlights societal asymmetries of status and power favoring men (Menegatti \& Rubini, 2018).

The third process is the use of metaphors to reinforce gender stereotypes by bringing together ordinarily unrelated categories based on some shared features (Eichstedt et al., 2002). For instance, flowers have been metaphorically linked to girls/women as both are considered delicate (Leinbach et al., 1997). Similarly, trees are considered metaphorically male (i.e., strong, tall; Eichstedt et al., 2002). Animals are also often the subject of metaphors, with bears and dogs being associated with boys/men (i.e., strong, aggressive) and birds, rabbits, cats, and butterflies with girls/women (i.e., delicate, soft; Leinbach et al., 1997). Other objects such as feathers, bows, and hearts are also associated more with girls/women (Leinbach et al., 1997). Children as young as 18 months old have been found to possess knowledge of gender metaphors (Eichstedt et al., 2002). Research on 
birth congratulation cards has provided mixed evidence for the presence of gender metaphors (Bridges, 1993; Willer, 2001). One study found that birds and rabbits were featured more on girl cards, whereas bears and dogs appeared more on boy cards (Bridges, 1993). However, in later studies no differences were found between boy and girl cards in the presentation of bears and rabbits (Christodoulou \& Lac, 2021; Willer, 2001). Flowers, ribbons, and hearts were more consistently used on girl cards in all three studies, but trees were not examined (Bridges, 1993; Christodoulou \& Lac, 2021; Willer, 2001). Last, sky objects, such as stars, sun, and moon, appeared more on boy cards in one of the studies (Willer, 2001), but these objects were not examined in the other studies. Sky objects and boys/men might be metaphorically linked as both could be considered to be above other(s) (in the hierarchy) or distant (Rudman et al., 2001).

The fourth process is the differential gender-stereotyped expectations that parents have for their children, which is found to be associated with parents' differential treatment of boys and girls (Endendijk et al., 2018). Three studies specifically examined the content of adults gender stereotyped expectations about children (Koenig, 2018; Martin, 1995; Powlishta, 2000). Taken together, adults expected boys to possess more masculine traits, such as being dominant, independent, competitive, aggressive, agentic, active, rebellious, noisy, and strong, compared to girls. On the other hand, girls were expected to possess more feminine traits, such as being gentle, neat/clean, sympathetic, eager to soothe hurt feelings, well-mannered, helpful, soft-spoken, communal, weak, shy, likeable, wholesome, overly emotional (e.g., crying), and feminine looking (e.g., dainty), compared to boys. When parents hold such different expectations of boys and girls they might describe their children in a gender-typical way on the birth announcement cards as well, ascribing more feminine traits and behaviors to newborn girls and masculine traits and behaviors to newborn boys. Research on birth congratulation cards demonstrated that feminine traits, such as being little and sweet, were used more on cards for girls than on cards for boys (Bridges, 1993; Willer, 2001). Yet, this difference was not found in online birth congratulation cards (Christodoulou \& Lac, 2021).

The last process is the parental preference for the gender of the child. This process is not included in the genderedfamily process model but was identified as important in previous research on birth announcements (Gonzalez \& Koestner, 2005). In most developed countries, parents prefer to have a child of each gender (McDougall et al., 1999). However, there is also plenty direct and indirect evidence for a son preference (especially for firstborns), indicated by selfreported attitudinal preferences for sons (Dahl \& Moretti, 2004), fathers' greater self-reported happiness after the birth of a son (Kohler et al., 2005), and greater father involvement and family stability in families with sons (Lundberg, 2005).
Parents' emotions expressed on birth announcement cards could also be an indication of parental gender preference, for instance when positive emotions are expressed more for one gender than another (Gonzalez \& Koestner, 2005). Previous research demonstrated that parents were more likely to express pride in birth announcements of boys (Gonzalez \& Koestner, 2005), and pride was also expressed more on birth congratulation cards for boys (Willer, 2001). Regarding the expression of happiness, the findings were less consistent. Parents were more likely to express happiness in birth announcements for girls (Gonzalez \& Koestner, 2005). Yet, happiness was expressed more on birth congratulation cards for boys than for girls (Bridges, 1993; Willer, 2001). In a sample of online birth congratulation cards, no differences were found in expressed happiness (Christodoulou \& Lac, 2021). Differences in findings for happiness might be attributed to difference in card type (i.e., parents expressing happiness vs. other people wishing happiness for the new parents or baby). Overall, these findings do not point to a clear son preference in birth announcements and birth congratulation cards, so more research is necessary.

\section{Historical Changes in Gender-Typed Content of Birth Announcement Cards}

Considering that sending out birth announcement cards has been common practice since the 1950 s, it is possible to examine historical changes in the gender content of these cards. Social role theory could provide relevant predictions for these historical changes (Wood \& Eagly, 2012). Central to social role theory is the prediction that gender differences arise from societies' division into gender roles: the female role of homemaker and the male role of economic provider. This sex-based division of labor leads to different (stereotypical) expectations for the behavior of men and women from observing men and women in these sex-based occupational and social roles. This theory predicts that as sex-based divisions of labor shift, so too will the associated gender stereotypes. In recent decades, the division of gender roles has become less strict in most modern Western societies (Wood \& Eagly, 2012) and gender stereotypes have indeed decreased over the course of the twentieth century (Bhatia \& Bhatia, 2021) as well as in the last decade (Charlesworth \& Banaji, 2021). Similarly, women's identification with stereotypically masculine traits increased from 1974 to 2012 (Donnelly \& Twenge, 2017). A specific aspect of birth announcement cards that could signal historical changes in gender roles is the order in which parents are mentioned on the card. As there is a power/status difference in gender roles, with the male role being associated with more power (Wood \& Eagly, 2012), it is likely that fathers are mentioned before mothers on the birth announcement cards, especially in older cards. 


\section{Current Study}

The current study is the first to examine the gender-typed content of a large sample of birth announcement cards $(\approx 5000)$, as well as historical changes between 1940 and 2019 in the gender-typed content of these cards. This study hereby extends a handful of small-scale studies that examined the gender-typed content of birth congratulation cards (Bridges, 1993; Christodoulou \& Lac, 2021; Willer, 2001) and birth announcements in newspapers (Gonzalez \& Koestner, 2005) at a single time point. More specifically, differences were investigated between birth announcement cards for boys and girls in the use of gender-typed colors, imagery, expressions, and labels. Based on past research, I hypothesized that the following content would occur with greater frequency in cards for boys than for girls: blue color and masculine toys (e.g., car, ball) (Hypothesis 1a), masculine animals (e.g., bear, dog), trees and sky objects (e.g., star, sun) (Hypothesis 1b), masculine traits (e.g., tough, strong) (Hypothesis 1c), expression of pride (e.g., "we proudly announce...") (Hypothesis 1d), and gender labels (e.g., boy, he) (Hypothesis 1e).

Further, I hypothesized that the following content would occur with greater frequency in cards for girls than for boys: pink color, feminine toys (e.g., doll, jewelry), and baby accessories (Hypothesis 2a), feminine animals (e.g., butterfly, rabbit), flowers, and feminine symbols (e.g., heart, bow, feather) (Hypothesis 2b), feminine traits (e.g., sweet, beautiful) (Hypothesis 2c), and expressions of joy (e.g., "we are happy to announce...") (Hypothesis 2d). Regarding historical changes in gender-typed content of birth announcement cards in the Netherlands, we hypothesized that observed differences in gender-typed content between boy and girl cards would decrease over time (Hypothesis 3a). In addition, the likelihood that fathers were mentioned before mothers on the cards was expected to decrease over time (Hypothesis $3 b$ ).

\section{Method}

\section{Sample}

Cards were selected for this study in two ways. First, the private collection of birth announcement cards of a collector was included. The collector retrieved these cards from midwifery practices, gynecology/birth wards of hospitals, doctor's practices, libraries, collectors' fairs, friends and family. The collection consisted of Dutch birth cards of children born between 1940 and 2018 from 885 unique birth places. Cards from 138 card designers and print shops were included. Second, this collection was supplemented with 249 cards from 2018 and 2019 retrieved from a birth ward of a hospital in the province of Utrecht, the Netherlands, and via the author's friends and family. The inclusion criteria were that cards had to include Dutch text, and were not for twins, adopted children, or still-born children. In total, 4669 cards were included in this study. On most of the cards $(n=3804,81.5 \%)$ the gender of the child was explicitly stated, with $41.5 \%$ of cards announcing the birth of a boy $(n=1939)$ and $40 \%$ announcing the birth of a girl $(n=1865)$. On $18.5 \%$ of the cards the gender of the child was not stated $(n=865)$. See Table 1 for the number of cards analyzed from each decade.

\section{Coding Categories}

A coding system was developed based on previous coding systems for birth announcements (Gonzalez \& Koestner, 2005) and birth congratulation cards (Bridges, 1993; Willer, 2001), as well as a thorough examination of a random sample of 100 cards from different birth years to check for other categories of interest. This combination of top-down and bottomup development of a coding scheme has been recommended for content analysis in gender research (Neuendorf, 2011). The coding system included categories for use of color, use of images, and use of text. Most of these codes (except the number of gender labels and use of color) were treated as dichotomous variables, reflecting the presence or absence of a certain type of text. As most cards included only one (or zero) instance of a certain type of image or text, it was more appropriate to use dichotomous data instead of count data.

\section{Use of Color}

This code indicated whether the dominant color in the card was pink, blue, or another color (i.e., any other color, no/ multiple colors).

\section{Use of Images}

Toys Coders listed all toys that were presented on the cards. The coded toys were subsequently recoded by the author into nominal variables reflecting the presence of

Table 1 Number and Percentage of Cards per Decade

\begin{tabular}{ll}
\hline Decade & $n(\%)$ of cards \\
\hline $1940-1950$ & $16(.3)$ \\
$1950-1960$ & $100(2.2)$ \\
$1960-1970$ & $185(4.0)$ \\
$1970-1980$ & $309(6.7)$ \\
$1980-1990$ & $585(12.6)$ \\
$1990-2000$ & $929(20.1)$ \\
$2000-2010$ & $1812(39.1)$ \\
$2010-2019$ & $694(15.0)$ \\
\hline
\end{tabular}


feminine toys or masculine toys. Toys were only categorized in the masculine and feminine categories when they were consistently labelled as masculine or feminine in previous research (Blakemore \& Centers, 2005; Endendijk et al., 2014; Kollmayer et al., 2018). Masculine toys included a car, race car, ball, airplane, train, motor bike, rocket, truck, fire truck, tractor, crane, sword, chopper, and catapult. Feminine toys included a doll, doll carrier, hulahoop, and jewelry.

Animals Coders listed all animals that were presented on the cards. The coded animals were subsequently recoded into nominal variables reflecting the presence of feminine animals (i.e., cat, butterfly, bird, rabbit) or masculine animals (i.e., bear, dog). Masculine and feminine animals were derived from metaphorically gendered animals used in previous research (Eichstedt et al., 2002; Leinbach et al., 1997).

Flora Coders listed all types of flora included (e.g., flowers, trees, bushes, grass, four-leaved clover). These codes were subsequently recoded into nominal variables reflecting the presence of flowers (e.g., flower, rose, tulip, lily) or trees (e.g., apple tree, palm tree, tree).

Baby Accessories Coders listed all baby accessories depicted on the card (e.g., pacifier, baby bottle, crib, clothes, shoes). These codes were subsequently recoded into a nominal variable reflecting the presence of any baby accessories.

Sky Objects Coders listed all objects from the sky that were presented on the cards (e.g., sun, moon, star, cloud). The coded sky objects were subsequently recoded into a nominal variable reflecting the presence of any sky object.

Depiction of Baby This code reflected whether the card depicted an image of the baby that was born (either a drawing or a picture).

Other Symbols Coders also listed any other symbols present on the cards that were not captured by the above categories. In these codes, several metaphorically feminine symbols could be identified (i.e., heart, bow, feather, female sex symbol, rosette, fairy; Eichstedt et al., 2002; Leinbach et al., 1997), which were recoded into a nominal variable reflecting the presence of other feminine symbols.

\section{Use of Text}

Card Gender This code reflected whether the gender of the child that was born was explicitly stated on the card as boy (e.g., boy, son, brother, he, him, his) or girl (e.g., girl, daughter, sister, she, her), or gender was not mentioned.
Descriptions of Child Coders listed all descriptions that referred to the character, appearance, or behavior of the child that was born. Subsequently, the author coded the characteristics into nominal variables for feminine and masculine descriptions using content from the Bem Sex-Role Inventory (Bem, 1981) and the Children's Occupations, Activities, and Traits (COAT) questionnaire (Liben \& Bigler, 2002) to inform the descriptions. Masculine characteristics included tough, naughty, energetic, noisy, strong, healthy, big, unique, free, dangerous, imperial, fit, forceful, lively. Feminine characteristics included small, weak, beautiful, sweet, neat, cute, dependent, soft, young, cheerful, delicate, affectionate, powerless, innocent, gullible.

Emotions Coders noted all emotions that were expressed on the card. As there were specific hypotheses about the emotions of happiness and pride, nominal variables for the inclusion of happiness (indicated by keywords pleased, happy, delighted, hooray, yippie) and pride (indicated by keywords pride, proud) were created.

Order of Parents Coders indicated the order in which mother and father of the child were mentioned $(1=$ father's name before mother's name, $2=$ mother's name before father's name, 3 = unclear, missing, or only one parent named). For most cards, the fathers were mentioned first (77.5\%) and only $2.6 \%$ of cards were coded under the third category. Therefore, the author recoded this variable into a nominal variable reflecting whether fathers were mentioned first versus not.

Gender Labels Coders listed the number of gender labels (e.g., boy, son, brother, he, him, his, or girl, daughter, sister, she, her) that were used to label the child on the card.

\section{Coding Procedure}

Cards were coded by a group of 19 coders (i.e., bachelor students in Clinical, Child, Family, and Education Studies, a research assistant, the author). The coders were trained by the author in using the coding system in five weekly 2-h training sessions. In between sessions, coders categorized the content of 10 predetermined cards as homework for the next session. In the fifth session coders reached 90-100\% agreement with the consensus score on the cards that had to be coded as homework. After the training, coders' interrater reliability was determined on a sample of 60 cards. Except for the author, coders were unaware of the study's research question and hypotheses. Coders were not blind to the gender of the child on the card, as this was one of the variables that had to be coded. See Table 2 for an overview of the coder reliability statistics. Ranges for kappa's, ICCs, Krippendorff's alphas, and percentage agreement indicated 
Table 2 Reliability of Coders with Consensus Scores

\begin{tabular}{|c|c|c|}
\hline Variable & ICC/Kappa ${ }^{a}$ & $\begin{array}{l}\text { Krippendorff's } \\
\text { alpha }\end{array}$ \\
\hline Gender card & $.97-1.00$ & .99 \\
\hline Gender labels & $.95-1.00$ & .99 \\
\hline Color card & $.91-1.00$ & .92 \\
\hline \multicolumn{3}{|l|}{ Toys } \\
\hline Masculine $^{\mathrm{b}}$ & $99-100 \%$ & NA \\
\hline Feminine $^{b}$ & $99-100 \%$ & NA \\
\hline \multicolumn{3}{|l|}{ Animals } \\
\hline Masculine $^{\mathrm{b}}$ & $93-100 \%$ & NA \\
\hline Feminine & $.87-1.00$ & .91 \\
\hline \multicolumn{3}{|l|}{ Flora } \\
\hline Flowers & $.89-1.00$ & .94 \\
\hline Trees $^{b}$ & $100 \%$ & NA \\
\hline Baby accessories & $.80-1.00$ & .91 \\
\hline Sky objects & $.66-1.00$ & .86 \\
\hline Baby & $.91-1.00$ & .99 \\
\hline Other feminine symbols ${ }^{\mathrm{b}}$ & $95-100 \%$ & NA \\
\hline \multicolumn{3}{|l|}{ Descriptions of child } \\
\hline Masculine $^{\mathrm{b}}$ & $98-100 \%$ & NA \\
\hline Feminine & $.83-1.00$ & .90 \\
\hline \multicolumn{3}{|l|}{ Positive emotions } \\
\hline Joy & $.93-1.00$ & .97 \\
\hline Pride & 1.00 & 1.00 \\
\hline Order parents' names listed & $.71-1.00$ & .88 \\
\hline
\end{tabular}

$N A=$ not applicable

${ }^{a}$ Intraclass correlation was computed for continuous variables (i.e., number of gender labels). Kappa was calculated for nominal variables

${ }^{b}$ For these variables percentage agreement was calculated because there were too few cards with these codes included in the reliability set to compute kappa or Krippendorff's alpha

good to excellent coder reliability across all coded categories (Fleiss, 1981; Hayes \& Krippendorff, 2007).

\section{Data Analysis}

All analyses were conducted in SPSS. First, chi-square tests were conducted to examine gender differences in the inclusion of colors (pink, blue, other), different types of imagery (toys, animals, flora, baby accessories, sky objects, the baby, other feminine symbols), and different types of text (descriptions of child, joy, pride) in the birth announcement cards. Only variables for which significant gender differences were found on these descriptive analyses were entered into a multinomial logistic regression. This logistic regression analysis was used to predict card gender (i.e., boy card, girl card, nongender-specific card) from the use of color, the inclusion of different types of illustrations, and different types of text. Second, a separate logistic regression analysis was conducted in which card gender (i.e., boy card, girl card) was predicted from the number of gender labels used in the card. A separate analysis was necessary in this regard, because the number of gender labels could only be compared between boy and girl cards as the nongender-specific cards did not include any gender labels. In both analyses predicting card gender, girl cards were the reference category, which enabled a comparison between boy and girl cards to test the hypotheses about gender differences in card content.

Third, interactions between birth year (mean centered) and the variables reflecting the use of colors and the inclusion of different types of imagery and text were added to the two logistic regression models described above. This allowed for testing whether the prediction of card gender from its contents changed over time, or in other words whether there were changes in the gender-typed content of the birth cards over time. Fourth, a logistic regression analysis was conducted predicting whether fathers were mentioned before mothers to test the hypothesis that over time it became less likely that fathers were mentioned first on birth announcement cards.

\section{Results}

\section{Descriptive Statistics and Gender Differences}

Table 3 presents descriptive statistics for the type of colors, images, and text that were used in the birth announcement cards. In terms of colors, blue was used most often (19\%). The most frequently included image was an image of the baby that was born (48\%). The expression of joy was included in about half of the cards (48\%). Feminine toys and trees were the least frequently included in the cards $(<5 \%)$. Chi-square tests revealed blue occurred with greater frequency in boy cards (in line with H1a), whereas pink occurred with greater frequency in girl cards (in line with H2a), $\chi^{2}(2)=369.18, p<.001$, Cramer's $V=.31$. In line with Hypotheses 1a, 1c, and 1d, gender-typed content occurred with greater frequency in boy cards than in girl cards for the following: masculine toys, $\chi^{2}(1)=7.25, p=.007$, Cramer's $V=.04$, masculine descriptions of the child, $\chi^{2}(1)=4.12$, $p=.042$, Cramer's $V=.03$, and pride, $\chi^{2}(1)=4.00, p=.046$, Cramer's $V=.03$. In line with Hypothesis $2 b$, gender-typed content occurred with greater frequency in girl cards than in boy cards for the following: flowers, $\chi^{2}(1)=26.11, p<.001$, Cramer's $V=.08$, and feminine symbols, $\chi^{2}(1)=9.53$, $p=.002$, Cramer's $V=.05$. No gender differences were found for the other gender-typed content variables ( $p$ 's $>.112$ ), which did not support Hypothesis $1 \mathrm{~b}$ (animals, trees, sky objects), Hypothesis 2a (feminine toys), Hypothesis $2 \mathrm{~b}$ (feminine animals), Hypothesis 2c (feminine traits), or Hypothesis $2 \mathrm{~d}$ (joy). In sum, Hypotheses 1a, 1c, and 1d were fully supported, partial support was found for Hypotheses $2 \mathrm{a}$ and $2 \mathrm{~b}$, and no support was found for Hypotheses $1 \mathrm{~b}, 2 \mathrm{c}$, or $2 \mathrm{~d}$. 
Table 3 Descriptive Statistics of Colors, Images, and Text Included in Birth Cards

\begin{tabular}{|c|c|c|c|c|}
\hline \multirow[b]{3}{*}{ Variable } & \multirow{3}{*}{$\begin{array}{l}\text { All cards } \\
n(\%)\end{array}$} & \multicolumn{3}{|l|}{ Card type } \\
\hline & & Boy card & Girl card & $\begin{array}{l}\text { Gender not } \\
\text { mentioned }\end{array}$ \\
\hline & & $n(\%)$ & $n(\%)$ & $n(\%)$ \\
\hline \multicolumn{5}{|l|}{ Color card } \\
\hline Pink & $463(10)$ & $40(2)$ & 339 (18) & $84(10)$ \\
\hline Blue & $898(19)$ & $524(27)$ & 211 & $163(19)$ \\
\hline \multicolumn{5}{|l|}{ Images } \\
\hline \multicolumn{5}{|l|}{ Toys } \\
\hline Feminine toy & $66(1)$ & $29(1)$ & $28(2)$ & $9(1)$ \\
\hline Masculine toy & $253(5)$ & $126(6)$ & $84(5)$ & $43(5)$ \\
\hline \multicolumn{5}{|l|}{ Animals } \\
\hline Feminine animal & $428(9)$ & $177(9)$ & $171(9)$ & $80(9)$ \\
\hline Masculine animal & $386(8)$ & $174(9)$ & $152(8)$ & $60(7)$ \\
\hline \multicolumn{5}{|l|}{ Flora } \\
\hline Flowers & $828(18)$ & $291(15)$ & $399(21)$ & $138(16)$ \\
\hline Trees & $151(3)$ & $59(3)$ & $52(3)$ & $40(5)$ \\
\hline Baby accessories & $965(21)$ & $420(22)$ & $402(22)$ & $143(17)$ \\
\hline Sky objects & $524(11)$ & $229(12)$ & $205(11)$ & $90(10)$ \\
\hline Baby & $2231(48)$ & $952(49)$ & $896(48)$ & $383(44)$ \\
\hline Other feminine symbols & $746(16)$ & $275(14)$ & $335(18)$ & $136(16)$ \\
\hline \multicolumn{5}{|l|}{ Text } \\
\hline \multicolumn{5}{|l|}{ Descriptions of child } \\
\hline Feminine descriptions & $696(15)$ & $282(15)$ & $306(16)$ & $108(12)$ \\
\hline Masculine descriptions & $267(6)$ & $130(7)$ & $96(5)$ & $41(5)$ \\
\hline \multicolumn{5}{|l|}{ Positive emotions } \\
\hline Pride & $374(8)$ & $169(9)$ & $130(7)$ & $75(9)$ \\
\hline Joy & $2263(48)$ & $1054(54)$ & $1002(54)$ & $207(24)$ \\
\hline Order parents (father first) & $3618(77)$ & $1520(78)$ & $1476(79)$ & $622(72)$ \\
\hline Number of gender labels, $M(S D)$ & $1.95(1.07)$ & $1.95(1.13)$ & $1.96(1.01)$ & NA \\
\hline
\end{tabular}

Percentages are based on the total number of cards in which a certain type of color, image, or text was used (all cards: $N=4669$, boy cards: $n=1939$, girl cards: $n=1865$, cards without gender labels: $n=865$ ). Percentages in bold represent a significant gender difference found with chi-square tests, $p<.05$

$N A=$ not applicable

\section{Predicting Card Gender from Use of Color, Types of Imagery, and Text}

Table 4 presents the results of the logistic regression analysis predicting card gender from the use of color, imagery, and text in birth announcement cards. The overall fit of the model was significant, $\chi^{2}(14)=451.34, p<.001$. The model accounted for $9.2 \%$ of the variance (Cox and Snell Pseudo $R^{2}$ ) in card gender. Overall, the model correctly classified $49.6 \%$ of cards. Prediction was best for boy cards $(86.1 \%$ correct), followed by girl cards ( $34.9 \%$ correct).

The following gender-typed content contributed significantly to the prediction of card gender: pink color, blue color, flowers, masculine descriptions of the child, and pride. In line with Hypothesis 1a and 2a, for boy cards, the odds of having pink as a dominant color were .12 times smaller than for girl cards, whereas the odds of having blue as a dominant color were 2.42 times larger than for girl cards. In line with Hypothesis $1 \mathrm{~b}$, the odds that boy cards depicted flowers were .68 times smaller compared to girl cards. Supporting Hypothesis 1c, the odds that masculine descriptions of the child were included on boy cards were 1.33 times larger than such descriptions being included on girl cards. Last, the odds that the emotion pride was mentioned were 1.42 times larger for boy cards than for girl cards, which supported Hypothesis 1d. Boy cards and girl cards did not differ in the odds of including images of masculine toys (inconsistent with H1a) and other feminine symbols (inconsistent with $\mathrm{H} 2 \mathrm{~b}$ ). A separate logistic regression revealed that number of gender labels also did not differ between boy and girl cards, $B=-.01, S E B=.03$, Wald $=.03$, OR $=.995, p=.86$, $95 \%$ CI [.94, 1.06], which did not support Hypothesis 1e. 
Table 4 Outcomes of a Logistic Regression Analysis Testing Differences Between Boy and Girl Birth Announcement Cards in Colors, Types of Illustrations, and Types of Text

\begin{tabular}{llllllll}
\hline Card & Variable & $B$ & $S E$ & Wald & $p$ & OR & $95 \% C I$ \\
\hline Boy $^{\mathrm{a}}$ & & & & & & & \\
& Intercept & .07 & .05 & 2.15 & .142 & & \\
& Color: Pink & -2.15 & .17 & 154.71 & .000 & .12 & {$[.08, .16]$} \\
& Color: Blue & .88 & .09 & 94.78 & .000 & 2.42 & {$[2.03,2.89]$} \\
& Toys: Masculine & .20 & .15 & 1.72 & .189 & 1.22 & {$[.91,1.63]$} \\
& Flowers & -.39 & .09 & 18.52 & .000 & .68 & {$[.57, .81]$} \\
& Other feminine symbols & -.17 & .12 & 1.85 & .174 & .85 & {$[.66,1.08]$} \\
& Masculine descriptions of child & .29 & .15 & 3.93 & .047 & 1.33 & {$[1.00,1.77]$} \\
& Pride & .35 & .13 & 7.17 & .007 & 1.42 & {$[1.10,1.83]$} \\
\hline
\end{tabular}

${ }^{a}$ Reference category consists of girl cards. Results for the contrast between nongender-specific cards and girl cards were presented in Online Supplement
Because the hypotheses were specifically about differences between boy and girl cards, additional results for the differences between nongender-specific cards and girl cards are presented in Table S1 in the Online Supplement.

\section{Changes Over Time in Gender-Typed Content of Birth Announcement Cards}

In a second logistic regression analysis, interactions between birth year and use of color, imagery, and text were included in the model. The overall fit of the model was significant, $\chi^{2}(28)=505.28, p<.001$. The model accounted for $10.3 \%$ of the variance (Cox and Snell Pseudo $R^{2}$ ) in card gender. A likelihood ratio test revealed that the model with interactions fit the data better than the model without interactions, $\chi^{2}(14)=2821.60, p<.001$. Only significant interactions for the contrast comparing boy cards with girl cards were interpreted, because the hypothesis about historical change (H3a) was specifically about change in differences between boy and girl cards. Only two interactions were significant: the interaction between year and masculine descriptions of the child, $B=.04, S E B=.01$, Wald $=12.33, \mathrm{OR}=1.04, p<.001,95 \%$ $C I[1.02,1.06]$, and the interaction between year and pride, $B=-.04, S E B=.01$, Wald $=10.62, \mathrm{OR}=.97, p=.001,95 \%$ $C I[.95, .99]$. Simple slope analyses $\left(M_{\text {year }} \pm 1 S D\right)$ revealed that, in line with Hypothesis 3a, the odds for boy cards to include masculine descriptions were larger in cards before $1985, \mathrm{OR}=4.01, p=.08,95 \% C I[.85,19.01]$, than in cards after $2009, \mathrm{OR}=1.08, p=.83,95 \%$ CI [.57, 2.04]. In addition, the odds for boy cards to include descriptions of pride were smaller in cards before $1985, \mathrm{OR}=.49, p=.56,95 \%$ $C I[.04,5.45]$, than in cards after $2009, \mathrm{OR}=1.41, p=.14$, $95 \%$ CI [.90, 2.20], which did not support Hypothesis 3a.

A separate logistic regression analysis revealed that, in line with Hypothesis $3 \mathrm{~b}$, the odds of presenting father first on the cards (versus not presenting fathers first) decreased over time, $B=-.01, S E B=.003$, Wald $=22.61, \mathrm{OR}=.988$, $p<.001,95 \%$ CI $[.98, .99]$. The other separate logistic regression for number of gender labels, revealed that the number of gender labels in boy and girl cards did not change over time, $B=<.01, S E B=.002$, Wald $=.03, \mathrm{OR}=1.00$, $p=.87,95 \% C I[.996,1.005]$.

\section{Discussion}

The current study examined the gender-typed content of approximately 5000 birth announcement cards sent between 1940 until 2019. First, regarding gender-typed content, boy cards were more likely than girl cards to include blue as the dominant color, masculine descriptions of the child that was born, and parental expression of pride. On the other hand, girl cards were more likely than boy cards to include pink as the dominant color and images of flowers. For the 12 other types of gendered card content, no differences were found between boy and girl cards. Second, regarding historical changes in gender-typed content, the greater use of masculine descriptions on boy cards compared to girl cards decreased over time. Similarly, the likelihood that fathers were mentioned before mothers on the cards decreased over time. However, greater use of the emotion pride on boy cards compared to girl cards increased over time.

A first noteworthy finding of this study is that more gender-neutral than gender-typed content was included in birth announcement cards overall. Differences between boy and girl cards were found for only five of the 17 types of gender-typed content examined. In addition, for $18.5 \%$ of the cards, gender of the child was not explicitly stated, which might reflect that gender is not as salient of an attribute for these parents. The more gender-neutral content in birth announcement cards might reflect the Dutch cultural context in which gender equality is relatively high (United Nations Development Program, 2020; World Economic Forum, 2021), and people are reluctant to express gender stereotypes in explicit ways (Axinn et al., 2011).

The choices that parents did make about color, toys, or descriptions of the child's behavior in birth announcement 
cards could reflect other types of parental gender socialization that may occur later in the child's life. For instance, these choices could relate to the different toys and clothes parents buy for sons and daughters (Pomerleau et al., 1990), and the different ways parents react to certain behaviors in sons and daughters (Endendijk et al., 2017). The more gender-neutral content of birth announcement cards might indicate that the gender socialization process only commences to a minimal extent before or shortly after the birth of a child when parents make choices regarding birth announcement cards. It could be that parents do not yet think of their newborn child in a gendered way, and therefore do not engage in much gender socialization, which might also be reflected in making gender-neutral choices for birth announcement cards. This is a promising finding, considering that gender socialization has been linked to gender-inequality in language skills (Pruden \& Levine, 2017), academic achievement (Updegraff et al., 1996), occupational preferences (Sandberg et al., 1991), and problem behaviors in children (Endendijk et al., 2017). The finding that birth announcement cards included more gender-neutral than gender-typed content might also reflect those parents are reluctant to communicate gender stereotypes in explicit ways via the colors, images, and descriptions in birth announcement cards. Indeed, there is evidence that parents convey gender stereotypes via more implicit parenting practices, such as the evaluation of others' stereotypical and counter-stereotypical behaviors (Mesman $\&$ Groeneveld, 2018). More research is necessary to examine the different implicit ways parents engage in gender socialization with their children.

Not surprisingly the strongest evidence for gender-typed content in birth announcement cards was found for the colors blue and pink, which were more likely to be used for boys and girls, respectively. This finding is consistent with a large body of literature demonstrating the pink and blue worlds that are created for girls and boys through toys, clothes, and room décor (MacPhee \& Prendergast, 2019; Pomerleau et al., 1990), books and newspapers (Del Giudice, 2017), birth congratulation cards (Bridges, 1993; Willer, 2001), and before birth through gender-reveal parties (Gieseler, 2018). Using pink and blue as gender markers may trigger stereotypical thinking in children, even when the markers themselves (i.e., colors) are seemingly innocuous (Martin $\&$ Macrae, 2007). Indeed, preschoolers already have knowledge of color stereotypes (Picariello et al., 1990), which is known to guide their behavior, for instance choosing pink or blue items (Cunningham \& Macrae, 2011).

Birth announcement cards also included one instance of a gender metaphor with flowers occurring more frequently on cards for girls than boys. Flowers have been metaphorically linked to girls/women as both are considered delicate (Leinbach et al., 1997). In birth congratulation cards, the most consistent evidence for the inclusion of gender metaphors was found for flowers as well (Bridges, 1993; Christodoulou \& Lac, 2021; Willer, 2001). In the current study, no evidence was found for differences in the inclusion of any other gender metaphors about animals, sky objects, or other feminine symbols. An explanation for the lack of gender metaphors in birth announcement cards might be that gender metaphors for children are less strong than conventional stereotypes that are based on observing differences between men and women (Leinbach et al., 1997). Therefore, parents' gender metaphors might have guided their decisions regarding content of birth announcement cards in a minimal way. In addition, the specific lack of evidence for gender metaphors regarding animals could be attributed to inconsistencies in animal metaphors associated with men and women (Bock \& Burkley, 2019; Nilsen, 1996; Rodríguez, 2009).

Parents also described their newborn baby in a gendertyped way on the birth announcement cards, with masculine traits and behaviors such as strong, big, noisy, and energetic being used more on boy cards than on girl cards. These differential descriptions might reflect parents' different expectations about the characteristics and behaviors of boys and girls (i.e., expecting boys to possess more masculine traits than girls; Koenig, 2018; Martin, 1995; Powlishta, 2000). Such stereotyped expectations can have a powerful effect on parents' perception of and behavior toward children (Wood \& Eagly, 2012). For instance, parents with stereotyped expectations about boys and girls have been found to disapprove of children's gender-atypical behavior (Endendijk et al., 2014; Sandnabba \& Ahlberg, 1999), and in particular of boys' gender-atypical behavior (Sandnabba \& Ahlberg, 1999). That there was only a difference between boy and girl cards on masculine descriptions and not on feminine descriptions could reflect the more rigid nature of gender stereotypes for boys than for girls (Leaper, 2000).

Regarding expressed emotions on birth announcement cards, parents were more likely to express pride on cards for boys than on cards for girls, which provides minimal and indirect evidence for a son preference. This gender difference in expression of pride was also found in previous research on birth announcements (Gonzalez \& Koestner, 2005) and birth congratulation cards (Willer, 2001). As pride is experienced in response to events that might enhance one's social status (Gilbert, 2001), the greater expression of pride with boys might indicate that parents attribute more status to having a boy than to having a girl. Other positive emotions (i.e., happiness, overall positive emotions) were not expressed differently across boy and girl cards in the current study. Thus, Dutch parents' preference for sons might not be explicitly expressed, but may be evident in subtle indications that sons are valued more than daughters. Previous research also found small effects for a son preference in Western countries (Gonzalez \& Koestner, 2005; Kohler et al., 2005). 


\section{Historical Changes in Gender-Typed Content of Birth Announcement Cards}

Regarding historical changes in gender-typed content, two of the findings were in line with social role theory (Wood \& Eagly, 2012). First, the likelihood that fathers were mentioned before mothers on the cards decreased over time. Second, the greater use of masculine descriptions on boy cards compared to girl cards decreased over time. In recent decades, the division of gender roles has become less strict with women taking on the role of economic provider more often and men becoming more involved in household and child-care tasks (Wood \& Eagly, 2012). As gender roles have shifted over time (Bhatia \& Bhatia, 2021; Wood \& Eagly, 2012), men might have been viewed less as the 'head' of the family, making it less likely that the father would be mentioned before the mother on a birth announcement card. This shift might also explain the smaller differences in parents' attributions of masculine descriptions to boys versus girls in more recent birth announcement cards. That this smaller gender difference over time was only found for masculine traits could again be attributed to the more rigid gender roles for men/boys (Leaper, 2000). Because of the more rigid gender roles for men and boys, parents might be more reluctant to describe their newborn boys with feminine descriptions, than they are to describe their newborn girls with masculine descriptions. Similarly, women's identification with stereotypically masculine traits increased from 1974 to 2012, but no changes were found for feminine traits in either men or women (Donnelly \& Twenge, 2017).

In contrast with the decreases in gender-typed content observed over time, expressions of the emotion pride increased on boy cards compared to girl cards over time. This finding suggests that a preference for sons might be increasing instead of decreasing in the Netherlands. There is some evidence that son preferences have increased in developing countries over time (Filmer et al., 2008), although a similar increase has not been documented in Western countries (Chao et al., 2019). Research with Scandinavian samples does however indicate that greater equality in terms of gender roles does not necessarily neutralize gender preferences for children (Andersson et al., 2006). Changes in son preferences over time in Western countries might only be captured in implicit or indirect indications of son preferences, such as greater father involvement or marital stability (Lundberg, 2005), as social desirability bias has been found to confound parents' explicit reports of son preferences (Schief et al., 2019). The greater expression of pride on cards for boys over time might thus reflect an implicit rather than an explicit process. As the expression of pride might be a more implicit or subtle way of communicating a son preference, the increase in the expression of pride over time might not necessarily reflect an increase in son preference, but rather reflect a change in the indicators for showing this preference (i.e., more implicit, subtle).

\section{Limitations and Future Research Directions}

The findings of this study need to be viewed considering the limitations. First, the convenience sampling strategy used to select the birth announcement cards may limit the generalizability of the findings to the whole population of Dutch parents that send birth announcement cards. However, the cards included were sampled from 885 places of residence in the Netherlands (35\% of the total number of residences in the Netherlands) and 138 card designers and print shops, providing some support for the representativeness of the sample. Second, this study included relatively few cards from the 1940's and 1950's, which may have limited the power to detect changes in gender-typed content over time in earlier decades. Third, it was not coded whether the birth announcement card was for a first-born or later-born child, as this information was not always available from the card. Yet, evidence for son preferences is found more consistently for first-born children (Dahl \& Moretti, 2004; Kohler et al., 2005). Therefore, not being able to control for birth-order in the analyses may have confounded the results for parents' expression of positive emotions (i.e., joy, pride). Finally, a general problem with this type of content analysis of archival data is that the researcher does not know anything about the family that was sending the card. Many relevant aspects of the family (e.g., socioeconomic status, family composition, marital status) or of parents (e.g., gender stereotypes, knowledge of fetal sex before birth) may have contributed to parents' selections of the content of the birth announcement cards. These unknown variables may have affected the results of the current study. Future research could tackle this problem by asking parents to send in birth announcement cards together with some background information and questionnaires about variables of interest. However, with such a procedure it might be difficult to obtain such a large sample of birth announcement cards as was used in the present study.

Relatedly, because little was known about the families/ parents behind the card, the explanations offered here for the differences between boy and girl cards remain rather speculative. The speculations regarding the mechanisms underlying parents' choices for gender-typed content remain to be tested. For instance, future studies could examine associations between gender-typed content in birth announcement cards and parents' conventional and metaphorical gender stereotypes, views about gender roles, or stereotyped expectations about boys and girls characteristics. Similarly, future research should test the speculative hypotheses about the associations of gender-typed content in birth announcement 
cards with parents' gender socialization practices with their children and children's gender stereotype development.

\section{Practice Implications}

The findings of this study could be used to create awareness in parents, and people in general, of the gendered messages they convey to the world, and specifically to and about children. This study indicates that some parents start conveying gender-stereotypical messages about their child the moment a child is born, before children get to develop their own gender identity. These gendered messages can sometimes be very subtle, for instance in the differential expression of emotions or characteristics attributed to sons or daughters, and parents might not even be aware that they reinforce gender stereotypes in this way. These findings underscore how readily and early (before or shortly after birth) we start categorizing children into gender groups and creating pink and blue worlds for them. Such gender categorization and gendered messages seem to be ingrained in the Dutch normative practice of sending out birth announcement cards since the $1950 \mathrm{~s}$, and thereby contribute to the perpetuation of cultural gender stereotypes and gender roles. Regarding implications for future research, experimental studies could investigate the effects of exposure of adults and children to birth announcement cards that vary in gender-typed content. Such studies could shed light on the short-term and long-term effects of exposure to societal gender messages conveyed via normative practices.

\section{Conclusion}

This content analysis of a large sample of birth announcement cards revealed the presence of more gender-neutral than gender-typed content, which coincides with the finding that gender-typed content in birth announcement cards appears to have decreased over time. Despite the more gender-neutral content across the cards, this analysis did reveal several striking differences between girl and boy cards. In particular, the findings indicated that birth announcement cards including gender-typed content tended to reflect gender stereotypes and different gender expressions for boys and girls in subtle ways that may go undetected and continue to reinforce gender stereotypes. Consistent with aspects of the gendered-family process model (Endendijk et al., 2018), gender-typed content in birth announcement cards could reflect parents' endorsement of gender stereotypes, and the gender socialization practices they may employ to create a gendered environment for their children. Future research should continue to examine the content of other genderrelated normative practices and compare the gender messaging across these different practices and over time.
Supplementary Information The online version contains supplementary material available at https://doi.org/10.1007/s11199-021-01249-y.

Acknowledgements First, I am grateful for all the coding work that has been done by the bachelor students and my research assistant Joyce ter Heide. In addition, I would like to thank Marjanneke de Jong for providing and photographing her private collection of birth announcement cards. Last, I am thankful for the constructive feedback on the manuscript provided by Anneloes van Baar and Christel Portengen.

Author Contribution The author was solely responsible for the design and completion of the study and for writing the manuscript.

Funding This research was not supported by a specific funding instrument or grant.

Data Availability The birth announcement cards that were used for this study contain identifiable information (i.e., addresses, names, and phone numbers) of families. Therefore, they will not be made publicly available.

\section{Declarations}

Ethics Approval Not applicable, the study did not include human or animal subjects.

Consent to Participate Not applicable, the study did not include human or animal subjects.

Consent for Publication Not applicable, the study did not include human or animal subjects.

Conflicts of Interest There are no conflicts of interest to report.

Open Access This article is licensed under a Creative Commons Attribution 4.0 International License, which permits use, sharing, adaptation, distribution and reproduction in any medium or format, as long as you give appropriate credit to the original author(s) and the source, provide a link to the Creative Commons licence, and indicate if changes were made. The images or other third party material in this article are included in the article's Creative Commons licence, unless indicated otherwise in a credit line to the material. If material is not included in the article's Creative Commons licence and your intended use is not permitted by statutory regulation or exceeds the permitted use, you will need to obtain permission directly from the copyright holder. To view a copy of this licence, visit http://creativecommons.org/licenses/by/4.0/.

\section{References}

Andersson, G., Hank, K., Rønsen, M., \& Vikat, A. (2006). Gendering family composition: Sex preferences for children and childbearing behavior in the Nordic countries. Demography, 43(2), 255-267. https://doi.org/10.1353/dem.2006.0010

Axinn, W. G., Young-DeMarco, L., \& Ro, M. C. (2011). Gender double standards in parenting attitudes. Social Science Research, 40(2), 417-432. https://doi.org/10.1016/j.ssresearch.2010.08.010

Barnes, M. W. (2015). Anticipatory socialization of pregnant women: Learning fetal sex and gendered interactions. Sociological Perspectives, 58(2), 187-203. https://doi.org/10.1177/0731121414564883 
Barry, H., \& Harper, A. S. (1995). Increased choice of female phonetic attributes in first names. Sex Roles, 32(11-12), 809-819. https:// doi.org/10.1007/BF01560190

Bem, S. L. (1981). Bem Sex-Role Inventory: Professional manual. Consulting Psychologists Press.

Bhatia, N., \& Bhatia, S. (2021). Changes in gender stereotypes over time: a computational analysis. Psychology of Women Quarterly, 45(1), 106-125. https://doi.org/10.1177/0361684320977178

Blakemore, J. E. O., \& Centers, R. E. (2005). Characteristics of boys' and girls' toys. Sex Roles, 53(9), 619-633. https://doi.org/10.1007/ s11199-005-7729-0

Bridges, J. S. (1993). Pink or blue: Gender-stereotypic perceptions of infants as conveyed by birth congratulations cards. Psychology of Women Quarterly, 17(2), 193-205. https://doi.org/10.1111/j. 1471-6402.1993.tb00444.x

Bock, J., \& Burkley, M. (2019). On the prowl: Examining the impact of men-as-predators and women-as-prey metaphors on attitudes that perpetuate sexual violence. Sex Roles, 80(5), 262-276. https://doi. org/10.1007/s11199-018-0929-1

Chao, F., Gerland, P., Cook, A. R., \& Alkema, L. (2019). Systematic assessment of the sex ratio at birth for all countries and estimation of national imbalances and regional reference levels. Proceedings of the National Academy of Sciences, 116(19), 9303-9311. https:// doi.org/10.1073/pnas.1812593116

Charlesworth, T. E., \& Banaji, M. R. (2021). Patterns of implicit and explicit stereotypes III: Long-term change in gender stereotypes. Social Psychological and Personality Science. https://doi.org/10. $1177 / 1948550620988425$

Christodoulou, J., \& Lac, A. (2021). Examining the communication of gender roles to parents: a quantitative content analysis of online birth congratulations cards. Psychology \& Sexuality. https://doi. org/10.1080/19419899.2021.1902378

Crouter, A. C., Manke, B. A., \& McHale, S. M. (1995). The family context of gender intensification in early adolescence. Child Development, 66(2), 317-329. https://doi.org/10.2307/1131580

Cunningham, S. J., \& Macrae, C. N. (2011). The colour of gender stereotyping. British Journal of Psychology, 102(3), 598-614. https://doi.org/10.1111/j.2044-8295.2011.02023.x

Dahl, G. B., \& Moretti, E. (2004). The demand for sons: evidence from divorce, fertility, and shotgun marriage (Working Paper No. 10281). National Bureau of Economic Research, Cambridge. https://doi.org/10.3386/w10281

Del Giudice, M. (2017). Pink, blue, and gender: An update. Archives of Sexual Behavior, 46(6), 1555-1563. https://doi.org/10.1007/ s10508-017-1024-3

DeLoache, J. S., Cassidy, D. J., \& Carpenter, C. J. (1987). The three bears are all boys: Mothers' gender labeling of neutral picture book characters. Sex Roles, 17(3), 163-178. https://doi.org/10. 1007/BF00287623

Diesendruck, G., \& Deblinger-Tangi, R. (2014). The linguistic construction of social categories in toddlers. Child Development, 85(1), 114-123. https://doi.org/10.1111/cdev.12130

Donnelly, K., \& Twenge, J. M. (2017). Masculine and feminine traits on the Bem sex-role inventory, 1993-2012: A cross-temporal meta-analysis. Sex Roles, 76(9), 556-565. https://doi.org/10.1007/ s11199-016-0625-y

Eichstedt, J. A., Serbin, L. A., Poulin-Dubois, D., \& Sen, M. G. (2002). Of bears and men: Infants' knowledge of conventional and metaphorical gender stereotypes. Infant Behavior and Development, 25(3), 296-310. https://doi.org/10.1016/S0163-6383(02)00081-4

Endendijk, J. J., Groeneveld, M. G., van der Pol, L. D., van Berkel, S. R., Hallers-Haalboom, E. T., Mesman, J., \& Bakermans-Kranenburg, M. J. (2014). Boys don't play with dolls: Mothers' and fathers' gender talk during picture book reading. Parenting, 14(3-4), 141-161. https://doi.org/10.1080/15295192.2014.972753
Endendijk, J. J., Groeneveld, M. G., van der Pol, L. D., van Berkel, S. R., Hallers-Haalboom, E. T., Bakermans-Kranenburg, M. J., \& Mesman, J. (2017). Gender differences in child aggression: Relations with gender-differentiated parenting and parents' gender-role stereotypes. Child Development, 88(1), 299-316. https://doi.org/ $10.1111 / \mathrm{cdev} .12589$

Endendijk, J. J., Groeneveld, M. G., \& Mesman, J. (2018). The gendered family process model: An integrative framework of gender in the family. Archives of Sexual Behavior, 47(4), 877-904. https:// doi.org/10.1007/s10508-018-1185-8

Erwin, P. G. (1995). A review of the effects of personal name stereotypes. Representative Research in Social Psychology, 20, 41-52.

Filmer, D., Friedman, J., \& Schady, N. (2008). Development, modernization, and son preference in fertility decisions. World Bank Policy Research Working Paper, 4716, 1-33. https://doi.org/10. 1596/1813-9450-4716

Fisher-Thompson, D. (1993). Adult toy purchases for children: Factors affecting sex-typed toy selection. Journal of Applied Developmental Psychology, 14(3), 385-406. https://doi.org/10.1016/ 0193-3973(93)90016-O

Fleiss, J. L. (1981). Balanced incomplete block designs for inter-rater reliability studies. Applied Psychological Measurement, 5(1), 105-112. https://doi.org/10.1177/014662168100500115

Gelman, S. A., Taylor, M. G., \& Nguyen, S. P. (2004). Mother-child conversations about gender: Understanding the acquisition of essentialist beliefs. Monographs of the Society for Research in Child Development, 69(1), 1-127. https://doi.org/10.1111/j.0037976X.2004.00274.x

Gieseler, C. (2018). Gender-reveal parties: Performing community identity in pink and blue. Journal of Gender Studies, 27(6), 661671. https://doi.org/10.1080/09589236.2017.1287066

Gilbert, P. (2001). Evolution and social anxiety: The role of attraction, social competition, and social hierarchies. Psychiatric Clinics of North America, 24(4), 723-751. https://doi.org/10.1016/S0193953X(05)70260-4

Gonzalez, A. Q., \& Koestner, R. (2005). Parental preference for sex of newborn as reflected in positive affect in birth announcements. Sex Roles, 52(5), 407-411. https://doi.org/10.1007/ s11199-005-2683-4

Hayes, A. F., \& Krippendorff, K. (2007). Answering the call for a standard reliability measure for coding data. Communication Methods and Measures, 1(1), 77-89. https://doi.org/10.1080/ 19312450709336664

Hilliard, L. J., \& Liben, L. S. (2010). Differing levels of gender salience in preschool classrooms: Effects on children's gender attitudes and intergroup bias. Child Development, 81(6), 1787-1798. https:// doi.org/10.1111/j.1467-8624.2010.01510.x

Johnson, D. R., \& Scheuble, L. K. (2002). What should we call our kids? Choosing children's surnames when parents' last names differ. The Social Science Journal, 39(3), 419-429. https://doi.org/ 10.1016/S0362-3319(02)00203-3

Kessel, C., \& Kooger, S. (1996). Een verzameling van 35.000 geboortekaartjes [A collection of 35,000 birth announcement cards]. Traditie: Tijdschrift over Tradities en Trends, 2, 4-7. https://www.immaterieelerfgoed.nl/image/2018/9/19/traditie_ 1996_1_spread.pdf

Koenig, A. M. (2018). Comparing prescriptive and descriptive gender stereotypes about children, adults, and the elderly. Frontiers in Psychology, 9, 1086. https://doi.org/10.3389/fpsyg.2018.01086

Kohler, H. P., Behrman, J. R., \& Skytthe, A. (2005). Partner + children $=$ happiness? The effects of partnerships and fertility on wellbeing. Population and Development Review, 31(3), 407-445. https://doi.org/10.1111/j.1728-4457.2005.00078.x

Kollmayer, M., Schultes, M. T., Schober, B., Hodosi, T., \& Spiel, C. (2018). Parents' judgments about the desirability of toys for their children: Associations with gender role attitudes, gender-typing of 
toys, and demographics. Sex Roles, 79(5), 329-341. https://doi. org/10.1007/s11199-017-0882-4

Koningkaart. (n.d.). Geboortekaartjes [Birth announcement cards]. https://www.koningkaart.nl/geboortekaartjes.html

Leaper, C. (2000). The social construction and socialization of gender during development. In P. H. Miller \& E. Kofsky Scholnick (Eds.), Toward a feminist developmental psychology (pp. 127152). Taylor \& Frances/Routledge.

Leaver, T., \& Highfield, T. (2018). Visualising the ends of identity: Pre-birth and post-death on Instagram. Information, Communication, \& Society, 21(1), 30-45. https://doi.org/10.1080/1369118X. 2016.1259343

Leinbach, M. D., Hort, B. E., \& Fagot, B. I. (1997). Bears are for boys: Metaphorical associations in young children's gender stereotypes. Cognitive Development, 12(1), 107-130. https://doi.org/10.1016/ S0885-2014(97)90032-0

Liben, L. S., \& Bigler, R. S. (2002). The developmental course of gender differentiation: conceptualizing, measuring, and evaluating constructs and pathways. Monographs of the Society for Research in Child Development, 67(2), 1-183. https://doi.org/10.1111/ 1540-5834.t01-1-00188

Lieberson, S., Dumais, S., \& Baumann, S. (2000). The instability of androgynous names: The symbolic maintenance of gender boundaries. American Journal of Sociology, 105(5), 1249-1287. https:// doi.org/10.1086/210431

Lundberg, S. (2005). Sons, daughters, and parental behaviour. Oxford Review of Economic Policy, 21(3), 340-356. https://doi.org/10. 1093/oxrep/gri020

MacPhee, D., \& Prendergast, S. (2019). Room for improvement: Girls' and boys' home environments are still gendered. Sex Roles, 80(5), 332-346. https://doi.org/10.1007/s11199-018-0936-2

Martin, D., \& Macrae, C. N. (2007). A face with a cue: Exploring the inevitability of person categorization. European Journal of Social Psychology, 37(5), 806-816. https://doi.org/10.1002/ejsp.445

Martin, C. L. (1995). Stereotypes about children with traditional and nontraditional gender roles. Sex Roles, 33(11-12), 727-751. https://doi.org/10.1007/BF01544776

McDougall, J., Dewit, D. J., \& Ebanks, G. E. (1999). Parental preferences for sex of children in Canada. Sex Roles, 41(7), 615-626. https://doi.org/10.1023/A:1018803723262

Menegatti, M., \& Rubini, M. (2018). Gender bias and sexism in language. In H. Giles \& J. Harwood (Eds.), The Oxford encyclopedia of intergroup communication (Vol. 1, pp. 451-468). Oxford University Press.

Mesman, J., \& Groeneveld, M. G. (2018). Gendered parenting in early childhood: subtle but unmistakable if you know where to look. Child Development Perspectives, 12(1), 22-27. https://doi.org/ 10.1111/cdep. 12250

Neuendorf, K. A. (2011). Content analysis-a methodological primer for gender research. Sex Roles, 64(3-4), 276-289. https://doi.org/ 10.1007/s11199-010-9893-0

Nilsen, A. P. (1996). Of ladybugs and billy goats: What animal species names tell about human perceptions of gender. Metaphor and Symbol, 11(4), 257-271. https://doi.org/10.1207/s15327868ms1104_2

Noorlandt, J. (2019). Jongen of meisje: Culturele aspecten van 100 jaar geboortekaartjes [Boy or girl: Cultural aspects of 100 years of birth announcement cards]. Rhenen.

Picariello, M. L., Greenberg, D. N., \& Pillemer, D. B. (1990). Children's sex-related stereotyping of colors. Child Development, 61(5), 1453-1460. https://doi.org/10.1111/j.1467-8624.1990. tb02874.x
Pomerleau, A., Bolduc, D., Malcuit, G., \& Cossette, L. (1990). Pink or blue: Environmental gender stereotypes in the first two years of life. Sex Roles, 22(5-6), 359-367. https://doi.org/10.1007/ BF00288339

Powlishta, K. K. (2000). The effect of target age on the activation of gender stereotypes. Sex Roles, 42(3), 271-282. https://doi.org/10. 1023/A:1007095307977

Pruden, S. M., \& Levine, S. C. (2017). Parents's spatial language mediates a sex difference in preschoolers' spatial-language use. Psychological Science, 28(11), 1583-1596. https://doi.org/10.1177/ 0956797617711968

Rodríguez, I. L. (2009). Of women, bitches, chickens and vixens: Animal metaphors for women in English and Spanish. Culture, Language and Representation, 7, 77-100. https://www.raco.cat/ index.php/CLR/article/view/226358

Rudman, L. A., Greenwald, A. G., \& McGhee, D. E. (2001). Implicit selfconcept and evaluative implicit gender stereotypes: self and ingroup share desirable traits. Personality and Social Psychology Bulletin, 27(9), 1164-1178. https://doi.org/10.1177/0146167201279009

Sandberg, D. E., Ehrhardt, A. A., Ince, S. E., \& Meyer-Bahlburg, H. F. (1991). Gender differences in children's and adolescents' career aspirations: a follow-up study. Journal of Adolescent Research, 6(3), 371-386. https://doi.org/10.1177/074355489163007

Sandnabba, N. K., \& Ahlberg, C. (1999). Parents' attitudes and expectations about children's cross-gender behavior. Sex Roles, 40(3), 249-263. https://doi.org/10.1023/A:1018851005631

Schief, M., Vogt, S., Efferson, C. (2019) The structure of son bias in Armenia: from implicit associations to explicit behavior. Social Science Research Network Electronic Journal, Article 3469644. https://doi.org/10.2139/ssrn.3469644

United Nations Development Program. (2020). Human development reports: Gender inequality index. http://hdr.undp.org/ en/indicators/68606

Updegraff, K. A., McHale, S. M., \& Crouter, A. C. (1996). Gender roles in marriage: what do they mean for girls' and boys' school achievement? Journal of Youth and Adolescence, 25(1), 73-88. https://doi.org/10.1007/BF01537381

Weisgram, E. S., \& Bruun, S. T. (2018). Predictors of gender-typed toy purchases by prospective parents and mothers: the roles of childhood experiences and gender attitudes. Sex Roles, 79(5), 342-357. https://doi.org/10.1007/s11199-018-0928-2

West, E. (2010). Expressing the self through greeting card sentiment: Working theories of authentic communication in a commercial form. International Journal of Cultural Studies, 13(5), 451-469. https://doi.org/10.1177/1367877910372703Wong

Willer, L. R. (2001). Warning: Welcome to your world baby, gender message enclosed. An analysis of gender messages in birth congratulation cards. Women and Language, 24(1), 16-23.

Wood, W., \& Eagly, A. H. (2012). Biosocial construction of sex differences and similarities in behavior. In M. P. Zanna \& J. M. Olson (Eds.), Advances in Experimental Social Psychology (Vol. 46, pp. 55-123). Academic Press. https://doi.org/10.1016/B978-012-394281-4.00002-7

World Economic Forum. (2021). Global Gender Gap Report 2021. http://www3.weforum.org/docs/WEF_GGGR_2021.pdf

Publisher's Note Springer Nature remains neutral with regard to jurisdictional claims in published maps and institutional affiliations. 